and debate, which represents the breadth of respiratory and respiratory-related allergy seen by primary care practitioners globally. Being aw arded an Impact factor does help in this respect, but we are keen to take things further. In particular, we want to use social media to aid readers in interpreting study findings by bringing them into closer contact with authors and facilitating virtual, global discussions about various PCRJ papers and what they mean. We will have more to say on this at the turn of the year, but in the meantime we are delighted to note that this issue marks the launch of the new "education@pcrj" section of the Journal. In the very capable hands of section editors Hilary Pinnock and Jaime Correia de Sousa, this new education section is a formal manifestation of the second of the PCRJ's two aims, ${ }^{4}$ which we are sure will make an enormous contribution to bridging the gap between research and clinical practice. They present their plans for the future in their editorial on pg $133 .{ }^{5}$

We are very grateful to the PCRS-UK and the IPCRG, and the many organisations, institutions and individuals across the globe that have been fundamental in helping us achieve this important strategic goal. In particular, we thank all of our Assistant and Associate Editors and the members of the International Editorial Board for their support and expertise, and we again pay tribute to M ark Levy, Editor Emeritus, for his 15-year service as Editor-in-Chief and the legacy which he left.
The decision by Thomson-Reuters ISI to award the PCRJ an Impact factor is both timely and welcome. It now positions us to take a lead in advancing the frontiers of knowledge through publishing the very best research, discussion and debate on behalf of patients with respiratory problems worldwide. For a journal of record such as the PCRJ, this is the outcome that really matters...

Conflicts of interest The authors declare no relevant conflicts of interest in relation to this article.

17th May 2012; online 29th May 2012

(c) 2012 Primary Care Respiratory Society UK. All rights reserved

http://dx.doi.org/10.4104/pcrj.2012.00047

Prim Care Respir J 2012;21(2):121-2

\section{References}

1. Levy ML, on behalf of the editors of the Primary Care Respiratory Journal. Impact factor and its role in academic promotion. Prim Care Respir J 2009;13(3):127. http://dx.doi.org/10.4104/pcrj.2009.00051

2. Testa J. The Thomson Reuters Journal Selection Process (essay). http://thomsonreuters.com/products_services/science/free/essays/journal_selection_process/

3. Garfield E. Citation indexing - its theory and application in science, technology, and humanities. New York: John Wiley \& Sons, 1979

4. Stephenson P, Sheikh A. A tribute to the past, and plans for the future: helping to drive top quality primary care respiratory disease management worldwide. Prim Care Respir J 2011;20(1):1-3. http://dx.doi.org/10.4104/pcrj.2011.00013

5. Pinnock H, Correia de Sousa J. education@pcrj: the launch of a new initiative for the PCRJ. Prim Care Respir J 2011;21(2):133-4. http://dx.doi.org/10.4104/pcrj.2012.00048

\title{
A question of quality? A single questionnaire for measuring asthma control, structuring asthma reviews, and monitoring health service standards
}

See linked article by Kiotseridis et al. on pg 139

\section{*Hilary Pinnock ${ }^{a}$, Helen Lester ${ }^{b}$}

a Senior Clinical Research Fellow, Allergy and Respiratory Research Group, Centre for Population Health Sciences, The University of Edinburgh, Edinburgh, UK

b Professor of Primary Care, School of Health and Population Sciences, University of Birmingham, Birmingham, UK

*Correspondence: Dr Hilary Pinnock, Allergy and Respiratory Research Group, Centre for Population Health Sciences The University of Edinburgh, Doorway 3, Medical School, Teviot Place, Edinburgh, EH8 9AG, UK Tel: +44 (0)1316508102 Fax: +44 (0)131 6509119 E-mail: hilary.pinnock@ed.ac.uk

The paper describing the Active Life with Asthma (ALMA) questionnaire by Kiotseridis et al. ${ }^{1}$ in this issue of the Primary Care Respiratory Journal raises as many questions as it answers. The technical issue addressed in the paper about the validity of a subset of questions as an assessment of asthma control is arguably the simplest of the questions to answer. Derived appropriately from qualitative investigation, the 14 questions designed to measure control compared well with the 'gold standard' Asthma Control Questionnaire (ACQ). ${ }^{2}$ The more interesting questions, however, have yet to be addressed:

a) How do questionnaires fit into the well defined structure of a primary care consultation?

Experience in UK primary care where use of the Patient Health Questionnaire-9 (PHQ-9) was introduced as a measure of the severity of depression in the Quality and Outcomes Framew ork (QOF) in 2006 is not entirely encouraging. Although patients were relatively positive and considered that completing questionnaires made them feel as if they were being taken more seriously, ${ }^{4}$ general practitioners (GPs) thought that asking patients to complete a questionnaire was intrusive, interrupted the flow of the consultation, and added little to their clinical judgement. ${ }^{5}$ However, the International Primary Care Respiratory Group (IPCRG) in their recent prioritisation of research needs, identified the development of questionnaires (or just 'questions') as an important means of diagnosing and assessing respiratory conditions in the comparatively low-technology context of primary care. ${ }^{6}$ Objective assessment of control is a core component of asthma reviews which underpins management decisions.' The ALMA tool offers some validated morbidity questions, though how the questions can best be incorporated into an asthma consultation may be a practical concern for some clinicians. 
b) Will questionnaires be completed 'properly' in clinical practice?

The science underpinning the development of Patient Reported Outcome Measures (PROM s) emphasises the importance not only of the precise wording of questions but also of context and mode of delivery in ensuring that the instrument measures consistently what it is intended to measure. ${ }^{8}$ Instruments such as the $A C Q$ are validated by self-selected volunteer patients completing questionnaires under the supervision of trained researchers, and new modes of administration are carefully assessed to ensure that they do not compromise response rates or validity. ${ }^{9,10}$ Developers of questionnaires have long expressed the hope that their instrument will have clinical applicability, ${ }_{11}^{11}$ but in clinical practice such careful standardisation is unlikely, with clinicians adopting a range of practical strategies to overcome the challenges of time, language, poor literacy and perceived disruption of consultation. Experience with the PHQ-9 in the context of the QOF identified seven such strategies, ${ }^{12}$ (including incorporating paraphrased questions into the conversation and calculating a score after the consultation), thus completely negating validation. Although the questions used in the validation exercise reported by Kiotseridis et al. were obtained by selfcompletion of a (5-minute) paper questionnaire, the 'real-life' ALMA database is a (presumably clinician-completed) web-based application which immediately changes the dynamics of completion.

c) What impact does a template have on an asthma review?

The ALMA database, however, is more than another PROM assessing asthma control: it is a tool intended to structure asthma reviews. Structured asthma care, including assessment of control, has been shown to improve patient outcomes - for example, in the Australian $3+$ visit plan. ${ }^{13}$ Templates may be welcomed as a means of improving clinicians' adherence to protocols, ${ }^{14}$ though they have led to concerns about imposing a routine that potentially excludes the patient's agenda. ${ }^{15}$ Completing checklists may encourage the recording of negative findings that have not been explicitly elicited. ${ }^{16}$ The authors should consider recording asthma reviews or undertaking qualitative research to explore how the ALMA tool is applied, the impact it has on the process of the consultation, and crucially, whether identification of poor control triggers appropriate stepping up of treatment and improved outcomes for patients.

d) How might healthcare systems benefit?

There is a final question for the ALM A tool: can the questionnaire raise standards of care across a healthcare community? Routine use and the development of a database offers the opportunity to observe standards of practice and then to benchmark good practice as a first step to driving up quality of care. Although morbidity scores have been widely used to assess asthma control as part of initiatives to improve care across healthcare communities - for example in Finland ${ }^{17}$ and the USA ${ }^{18}$ - the data are generally collected by self-completed questionnaire as part of the evaluation of an initiative and thus do not reflect the real-life assessment of control using routinely collected data. The IPCRG Helping Asthma in Real Patients (HARP) study piloted in Ireland ${ }^{19}$ and now rolled out to the UK, Germany, France, Italy, Spain, Sweden, Norway and Australia uses some routinely collected data extracted from practice computer systems, but overcomes the lack of coded symptoms by sending questionnaires to people with asthma to assess morbidity.

By establishing a database of asthma assessments undertaken within the local healthcare community, the ALMA project has an important opportunity to monitor patient-related outcomes and the impact of initiatives on standards of care. An explicit focus on quality improvement is a key aim of the UK QOF. ${ }^{20}$ When $20 \%$ of practice income is attached to pay for performance indicators, motivation to achieve maximum points is high (UK practices achieved $98.7 \%$ of available asthma QOF points in 2010/1121). It will be interesting to compare the results of the voluntary ALM A scheme with the standards achieved in the financially-rewarded QOF.

\section{A question of quality}

The initiative described by Kiotseridis et al. provides an answer to one question: asthma control recorded by the ALMA questionnaire compares well to the gold standard ACQ. Time and further research will tell whether by structuring assessment of control it is possible to improve the quality of care provided to individual patients - and also, by routinely monitoring structured asthma reviews, raise the quality of asthma care within a healthcare community. The question is one of quality.

Conflicts of interest HP is an Associate Editor of the PCRJ, but was not involved in the editorial review of, nor the decision to publish, this article. HL works as the external contractor for NICE developing and piloting QOF indicators: her views are her own and do not represent those of NICE.

Funding HP is supported by a Primary Care Research Career Award from the Chief Scientist's Office, Scottish Government

Commissioned article; not externally peer-reviewed; accepted 31st January 2012; online 23rd March 2012

(c) 2012 Primary Care Respiratory Society UK. All rights reserved http://dx.doi.org/10.4104/pcrj.2012.00030

Prim Care Respir J 2012;21(2):122-4

\section{References}

1. Kiotseridis $H$, Bjermer $L$, Pilman E, et al. ALMA, a new tool for the management of asthma patients in clinical practice: development, validation and initial clinica findings. Prim Care Respir J 2012;21(2):139-44. http://dx.doi.org/10.4104/ pcrj.2011.00091

2. Juniper EF, Svensson K, Mork AC, Stahl E. Measurement properties and interpretation of three shortened versions of the asthma control questionnaire. Respir Med 2005;99:553-8. http://dx.doi.org/10.1016/j.rmed.2004.10.008

3. NHS Confederation, British Medical Association. New GMS Contract 2003: investing in general practice. London. March 2003

4. Leydon GM, Dowrick CF, McBride AS, et al. on behalf of the QOF Depression Study Team. Questionnaire severity measures for depression: a threat to the doctor-patient relationship? Br J Gen Pract 2011;61:117-23.

http://dx.doi.org/ 10.3399/bjgp11X556236

5. Dowrick C, Leydon GM, McBride A, et al. Patients' and doctors' views on depression severity questionnaires incentivised in UK quality and outcomes framework: qualitative study. BMJ 2009;338:b663

http://dx.doi.org/10.1136/ bmj.b663

6. Pinnock $\mathrm{H}$, Ostrem $\mathrm{A}$, Román Rodríguez $\mathrm{M}$ et al. Prioritising the respiratory research needs of primary care: the International Primary Care Respiratory Group (IPCRG) e-Delphi exercise. Prim Care Respir J 2012;21(1):19-27 http://dx.doi.org/10.4104/pcrj.2012.00006

7. Pinnock $\mathrm{H}$, Fletcher $\mathrm{M}$, Holmes $\mathrm{S}$, et al. Setting the standard for routine asthma consultations: a discussion of the aims, process and outcomes of reviewing people with asthma in primary care. Prim Care Respir J 2010;19:75-83. http://dx.doi.org/10.4104/pcrj.2010.00006 
8. Fitzpatrick R, Davey C, Buxton MJ, Jones DR. Evaluating patient-based outcome measures for use in clinical trials. Health Technology Assessment 1998;2(14):1-74.

9. Pinnock H, Sheikh A, Juniper E. Evaluation of an intervention to improve successful completion of the Mini-AQLQ: comparison of postal and supervised completion. Prim Care Respir J 2004;13:36-41. http://dx.doi.org/10.1016/j.pcrj.2003.11.004

10. Pinnock $H$, Sheikh $A$, Juniper $E$. Concordance between supervised and postal administration of the MiniAQLQ and ACQ is very high. J Clin Epidemiol 2005;58:809-14. http://dx.doi.org/10.1016/j.jclinepi.2005.01.010

11. Juniper EF, Bousquet J, Abetz L, Bateman ED. Identifying 'well-controlled' and 'not well-controlled' asthma using the Asthma Control Questionnaire. Respir Med 2006;100:616-21. http://dx.doi.org/10.1016/j.rmed.2005.08.012

12. Mitchell C, Dwyer R, Hagan T, Mathers N. Impact of the QOF and the NICE guideline in the diagnosis and management of depression: a qualitative study. $\mathrm{Br}$ J Gen Pract 2011;61:343-4. http://dx.doi.org/10.3399/bjgp11X572472

13. Glasgow NJ, Ponsonby A-L, Yates R, Beilby J, Dugdale P. Proactive asthma care in childhood: general practice based randomised controlled trial. BMJ 2003;327:65965. http://dx.doi.org/10.1136/bmj.327.7416.659

14. Ventres W, Kooienga S, Vuckovic N, Marlin R, Nygren P, Stewart V. Physicians, Patients, and the Electronic Health Record: An Ethnographic Analysis. Ann Fam Med 2006;4:124-1. http://dx.doi.org/10.1370/afm.425
15. Rhodes P, Langdon M, Rowley E, Wright J, Small N. What Does the Use of a Computerized Checklist Mean for Patient-Centered Care? The Example of a Routine Diabetes Review. Qualitative Health Research 2006;16:353-76. http://dx.doi.org/10.1177/1049732305282396

16. Brownbridge G, Evans A, Fitter M, Platts M. An interactive computerized protocol for the management of hypertension: effects on the general practitioner's clinical behaviour. J Royal Coll Gen Practitioners 1986;36:198-202.

17. Haahtela T, Klaukka T, Koskela K, et al. Asthma programme in Finland: a community problem needs community solutions. Thorax 2001;56:806-14. http://dx.doi.org/10.1136/thorax.56.10.806

18. Vollmer WM, Markson LE, O'Connor E, Frazier EA, Berger M, Buist AS. Association of Asthma Control with Health Care Utilization: A Prospective Evaluation. Am J Respir Crit Care Med 2002;165:195-9.

19. Sims EJ, for the HARP study group. Helping Asthma in Real Patients (The HARP study): Interim Report for the IPCRG. Available from http://www.theipcrg.org/resneeds/harp.php (accessed January 2012)

20. Department of Health. Equity and Excellence: Liberating the NHS. London: Department of Health, 2010 (Cm 7881)

21. The Information Centre. Quality and Outcomes Framework Achievement Data 2010/11. Available from http://www.ic.nhs.uk (accessed 8.1.12)

\section{Perceptions of risk may explain the discrepancy between patient and clinician-recorded symptoms}

\section{See linked article by Barbara et al. on pg 145}

\section{Ian Dawson ${ }^{\mathrm{a}}$, Victoria Senior ${ }^{\mathrm{b}}$ *Simon de Lusignanc}

a Lecturer in Human Resource Management \& Organisational Behaviour, The Surrey Business School, University of Surrey, UK

b Senior Lecturer in Health Psychology, School of Psychology, University of Surrey, UK

c Professor of Primary Care and Clinical Informatics, Department of Health Care Management and Policy, University of Surrey, UK

*Correspondence:

Professor Simon de Lusignan, Professor of Primary Care and Clinical Informatics, Department of Health Care Management and Policy, University of Surrey, Guildford, GU2 7PX, UK Tel: +44(0)1483 683089 Fax: +44(0)1483 686208 E-mail: s.lusignan@surrey.ac.uk

In this issue of the PCRJ, Barbara and colleagues ${ }^{1}$ report the agreement between patient-recorded and clinician-recorded symptoms of respiratory illness. Contrary to other research, the study revealed that the patients recorded fewer symptoms than were captured by the clinicians following consultation. Barbara et al.'s intriguing findings raise two key questions. First, what factors might cause patients to increase the quantity of the symptoms that they report when conversing with their clinician? Second, are there any reasons why clinicians may record symptoms in addition to the symptoms presented by the patients during consultation? We believe the answer to these questions may be explained by considering the psychological factors that may underlie patient and clinician symptom-recording behaviours. More specifically, we suggest that the different symptom-recording behaviours of patients and clinicians may be motivated by an intrinsic desire to manage perceived risks.

When patients visit their physician they often arrive with an agenda and expectation of receiving a prescription, particularly when they believe they have a respiratory illness. ${ }^{2,3}$ Such expectations seem reasonable given that patients typically visit their clinicians to obtain a solution (e.g. a prescription) to a problem (e.g. a respiratory infection). However, patients may perceive a risk that the clinician will not provide the anticipated solution and therefore not address the problem to a satisfactory standard. This perceived risk may be heightened as a result of the rise in public awareness of current campaigns to discourage clinicians from prescribing certain medications (e.g. antibiotics) due to costs, misuse and a slow decline in effectiveness (see Figure 1).,5 Consequently, patients may now perceive the risk of leaving the practice without an appropriate remedy as being much greater than in previous decades. In an attempt to manage this risk, we hypothesise that patients may report a greater quantity of symptoms during clinical consultations, with the intention of encouraging the clinician to diagnose an illness that would typically warrant a prescription. In short, the 'over-reporting' of symptoms by patients may lead some clinicians to record a greater quantity of symptoms than those recorded by the patient prior to the consultation. This thesis provides a potential explanation for Barbara et al.'s main finding that patients and clinicians record a different quantity of symptoms and for the contrast between this finding and findings observed in earlier work.

This notion is further supported by Barbara et al.'s finding that the symptoms which patients under-recorded (e.g. cough, fever, etc.) appear to be those that may be more difficult for a clinician to verify objectively in a short consultation. This behaviour may stem from the 